\title{
Prevalence of overweight and obesity in adult Nigerians - a systematic review
}

This article was published in the following Dove Press journal:

Diabetes, Metabolic Syndrome and Obesity:Targets and Therapy

21 January 2013

Number of times this article has been viewed

Innocent ljezie Chukwuonye'

Abali Chuku²

Collins John ${ }^{3}$

Kenneth Arinze Ohagwu'

Miracle Erinma Imoh ${ }^{4}$

Samson Ejiji Isa ${ }^{5}$

Okechukwu Samuel Ogah ${ }^{6}$

Efosa Oviasu ${ }^{7}$

'Department Of Internal

Medicine, Federal Medical Centre,

Umuahia, Nigeria; ${ }^{2}$ Department

Of Ophthalmology, Federal

Medical Centre, Umuahia, Nigeria;

${ }^{3}$ Department Of Paediatrics, Jos

University Teaching Hospital, Jos,

Nigeria; ${ }^{4}$ Department Of Family

Medicine, University Of Benin

Teaching Hospital, Benin City, Nigeria;

${ }^{5}$ Department Of Internal Medicine,

Jos University Teaching Hospital, Jos,

Nigeria; 'Department Of Internal

Medicine, University College Hospital, Ibadan, Nigeria; ${ }^{7}$ Department Of

Internal Medicine, University Of Benin

Teaching Hospital, Benin City, Nigeria

Correspondence: Innocent ljezie Chukwuonye Department of Internal Medicine/Psychiatry, Federal Medical Centre, PO Box 1229 Umuahia Branch Office, Umuahia, Abia State, Nigeria

Tel +23408038774307

Email chukwuonye4@yahoo.com
Background: Obesity is a major health problem, and there is an increasing trend of overweight and obese individuals in developing countries. Being overweight or obese is known to contribute significantly to morbidity and mortality rates in various countries around the world. We therefore aimed to identify and discuss current epidemiological data on the prevalence of obesity in Nigeria.

Method: A systematic review of papers published on the prevalence of obesity among adults in the country was carried out. We covered work published in MEDLINE, PubMed, Google, and African Journals Online using the terms "prevalence of overweight and obesity in Nigeria" or "overweight and obesity in Nigeria." In addition, personal inquiries were made. The search limits were articles published from January 2001 to September 2012. Only studies that used the body mass index to assess for overweight and obesity were included.

Results: Four studies met the inclusion criteria out of the 75 studies reviewed. In Nigeria, the prevalence of overweight individuals ranged from $20.3 \%-35.1 \%$, while the prevalence of obesity ranged from $8.1 \%-22.2 \%$.

Conclusion: The prevalence of overweight and obese individuals in Nigeria is of epidemic proportions. There is a need to pay closer attention to combating these health disorders.

Keywords: body mass index, BMI, obesity, overweight

\section{Introduction}

Noncommunicable diseases have overtaken communicable diseases as the leading causes of morbidity and mortality in Nigeria. ${ }^{1,2}$ The changing disease pattern has been traditionally attributed to recent advances in medicine resulting in the development of drugs and vaccines for the effective control of communicable diseases. Other factors driving this transition include changes in diet, cigarette smoking, alcohol consumption, and inadequate exercise. There is also rural to urban as well as fetal malnutrition, which predisposes individuals to development of noncommunicable diseases in adulthood. ${ }^{2}$ Among these noncommunicable diseases is obesity.

There are several classifications and definitions of obesity; however, the one commonly adopted is the definition by the World Health Organization (WHO), which defines obesity as a body mass index (BMI) of $30 \mathrm{~kg} / \mathrm{m}^{2}$ or more. ${ }^{3}$ In 2008 , more than 1.4 billion adults ( 20 years and above) were overweight, and of these over 200 million men and nearly 300 million women were obese. ${ }^{4}$ This data is alarming considering the health burden associated with these medical conditions. In addition, surveys have shown that the increasing trend of obesity in the world is even more pronounced in developing countries of the world..$^{5-7}$ Nigeria, a developing country, is the most populous country 
in Africa, with increasing changes in lifestyle and associated increasing burden of noncommunicable diseases.

Obesity is associated with major and minor diseases. The major diseases associated with obesity include hypertension, diabetes mellitus, and atherosclerosis, as well as certain types of cancer; there are also many additional less known complications of the disease. ${ }^{8}$ The medical costs associated with being overweight and obese are enormous, and involve direct and indirect costs. The direct medical costs usually include preventive, diagnostic, and treatment services related to obesity. The indirect costs are related to morbidity and mortality costs. Morbidity costs are defined as the value of income lost from decreased productivity, absenteeism, restricted activity, and hospital admission days. The mortality costs are the value of future income lost by the premature death of obese patients. In the United States of America, the total cost in 2008 was about 147 billion dollars. ${ }^{9-11}$ In Nigeria, there are no documented estimates from the available literature; however, the costs may run into several billions of naira a year, and therefore this necessitates serious attention from those who are involved in designing health programs at the federal, state, and local government levels.

To combat the menacing effects of being overweight or obese in Nigeria, there is a need to have a good knowledge of the prevalence of overweight and obesity in the country, and to address them appropriately. We sought to systematically review all existing literature on overweight and obesity in Nigeria and to establish the prevalence and trends of obesity. Presently, there are several papers on overweight and obesity in Nigeria; ${ }^{12-14}$ however, there is a dearth of review articles on this topic in this country.

\section{Method}

We conducted a systematic review of studies published from January 1, 2001 to September 30, 2012, using the search terms, "prevalence of overweight and obesity in Nigeria" or "overweight and obesity in Nigeria." We decided to conduct a review of the prevalence of overweight and obesity in Nigeria from 2001 because it was around that year that the fast food industry became very popular in Nigeria and started receiving high levels of patronage, especially in cities and towns.

In order to eliminate difficulties in analyzing the data, we paid attention to surveys that made use of BMI only in the definition of overweight and obesity. Another common method of determining obesity was by using waist circumference measurements. However, in most studies that were available on abdominal obesity, ${ }^{14-17}$ the protocols for measuring waist circumference were not the same. This makes it difficult to compare most of these studies. Also, there are no universally acceptable cut-off criteria for defining abdominal obesity, given the existence of different criteria (including the International Diabetes Foundation, ${ }^{18}$ and the Adult Treatment Panel III, ${ }^{19}$ which are the more prominent criteria), and there are also different cut-offs for obesity for men and women. Moreover, waist circumference measurements do not have cut-off scores for being overweight, which is one of the parameters that we are looking at in this review. The above limitations of the waist circumference method contributed to our adopting only studies that used BMI (the WHO standard) in determining overweight and obesity. BMI was classified as follows: ${ }^{3}$ overweight, BMI of $25-29.9 \mathrm{~kg} / \mathrm{m}^{2}$; and obesity, BMI of $\geq 30 \mathrm{~kg} / \mathrm{m}^{2}$.

We covered studies published in MEDLINE ${ }^{\circledR}$, PubMed, the African Journal Online, and Google Scholar. The articles collected were those published in the English language, the official language of Nigeria. The search limit included articles that were published from January 1, 2001 to September 30, 2012 as stated earlier.

Criteria for the inclusion of articles are as follows:

1. The study should cut across all age groups to a reasonable extent.

2. BMI was used to determine overweight and obesity.

3. The location of the study in Nigeria was stated.

4. Stratification of overweight and obesity was clearly spelt out.

5. The survey should involve both males and females.

6. The study was not limited to a particular profession (eg, traders alone).

\section{Validation of search results}

The search results were validated in three stages, as follows:

1. All relevant article abstracts were discovered by using the search terms, "prevalence of overweight and obesity in Nigeria" or "overweight and obesity in Nigeria" published from January 1, 2001 to September 30, 2012, and those that were available on the indicated databases during the period of this review were included.

2. All articles not meeting the inclusion criteria as stated above were later discarded.

3. The full-text versions of the articles that met the inclusion criteria were obtained and reviewed by two or more researchers independently. Any controversies surrounding any particular included or excluded paper were discussed by all the authors, and a collective decision was taken on the article. 
In instances where more than one survey was obtained from a city or state, only the most recent study was included in the present research.

\section{Results}

The search on the prevalence of overweight and obesity returned a total of 75 abstracts; however, only four of the abstracts met the inclusion criteria, and the full surveys were obtained either from the Internet or from the authors by correspondence. ${ }^{13,20-22}$ The prevalence range of being overweight was $20.3 \%-35.1 \%$, while the prevalence range of obesity was $8.1 \%-22.2 \%$. The lowest prevalence of being overweight was $20.3 \%$ and this was observed at Ile Ife; ${ }^{21}$ meanwhile, the highest prevalence rate was observed at Ilorin $(35.1 \%) .{ }^{22}$ The lowest prevalence of obesity was observed at Maiduguri (8.1\%), while the highest was observed at Lagos $(22.2 \%)$ (Table 1$){ }^{13}$

Three of the studies stratified the prevalence of overweight and obesity based on age and sex. Amira et $\mathrm{al}^{13}$ conducted a community-based screening for chronic kidney disease risk factors during the World Kidney Day activities over the course of 5 years in Lagos metropolis (South West Nigeria) with an estimated population of 10 million. The subjects were classified by sex ( $52.6 \%$ male, $47.4 \%$ female) and into the age ranges $15-24,25-34,35-44,45-54$, 55-64, 65-74, and 75 years and above. Overweight rates were $33.3 \%$ of the males and $31.9 \%$ of the females, and obesity rates were $15.7 \%$ and $29.5 \%$, respectively. In men, overweight and obesity were highest among the age range of 55-64 years ( $45.0 \%$ and $22.5 \%$, respectively), and lowest among the age range $15-24$ (11.9\%, and $2.4 \%$, respectively). In women, overweight and obesity were highest in the age range $35-44$ (36.4\% and $35.8 \%$, respectively), and the lowest prevalence of overweight and obesity was in the age range $15-24$ (15.1\% and 3.8\%, respectively). Oyeyemi et $\mathrm{al}^{20}$ carried out a cross-sectional study. Participants were systematically recruited from 38 neighborhoods and were categorized into high and low socioeconomic status by the Ministry of Urban Planning and Development in Maiduguri. It is worth noting that Maiduguri is the capital city (and the largest city) in Borno State, North Eastern Nigeria. They did not stratify the prevalence based on age range; however, there was sex stratification: $60.1 \%$ and $39.9 \%$ of the participants were males and females, respectively; $29.2 \%$ of the males and $33.8 \%$ of the females were either overweight or obese.

Adedoyin et al ${ }^{21}$ also conducted a cross-sectional study at Ile-Ife using the WHO guidelines for conducting community-based studies. However, the authors did not state the period during which the study was conducted. Subjects were stratified by sex and into the age ranges 20-29, 30-39, 40-49, 50-59, 60-69, and 70 years and above. The rates of overweight and obesity were $20.3 \%$ and $12.5 \%$, respectively, and were higher in females than in males. In men, overweight and obesity were highest in the age range $60-69$ years $(30.4 \%$ and $17.4 \%$, respectively), and lowest in the age range $20-29$ years $(7.9 \%$, and $2.6 \%$, respectively). In women, overweight and obesity were highest in the age range 70 and above $(32.6 \%$ and $20.9 \%$, respectively), and the lowest prevalence of overweight and obesity was in the age range $20-29$ years $(14.4 \%$ and $8.3 \%$, respectively). In addition, Desalu et $\mathrm{al}^{22}$ conducted a cross-sectional study of individuals aged 18 years and older in the Ilorin East and West local governments (in the north-central region of Nigeria) from March 2006 to June 2006. The subjects (men and women together) were stratified into the age ranges 18-19, 20-29, 30-39, 40-49, $50-59$, and 60 years and above. The researchers noted that $62.0 \%$ and $38.0 \%$ of the participants were males and females, respectively, and that $2.4 \%$ of males and $7.4 \%$ of females were obese. The highest prevalence of obesity was obtained in the age range 40-49 years (49.4\%). The lowest prevalence of obesity was observed in the age range $18-19$ years $(1.3 \%)$.

Table I Studies on the prevalence of overweight and obesity that met the inclusion criteria in the review

\begin{tabular}{lllllll}
\hline Ref & $\begin{array}{l}\text { Study } \\
\text { location }\end{array}$ & $\begin{array}{l}\text { Sample } \\
\text { size }\end{array}$ & $\begin{array}{l}\text { Age } \\
\text { (years) }\end{array}$ & $\begin{array}{l}\text { Obese } \\
\text { (\%) }\end{array}$ & $\begin{array}{l}\text { Overweight } \\
\text { (\%) }\end{array}$ & $\begin{array}{l}\text { Period } \\
\text { of study }\end{array}$ \\
\hline 13 & Lagos & 1368 & $15-75$ & 22.2 & 32.7 & $2006-2010$ \\
20 & Maiduguri & 1818 & $20-65$ & 8.1 & 22.8 & $\begin{array}{l}\text { August 2010 to } \\
\text { September 201I }\end{array}$ \\
21 & lle Ife & 2097 & 21 and above & 12.5 & 20.3 & Not stated \\
22 & llorin & 810 & $18-65$ & 9.8 & 35.1 & March 2006 to \\
& & & & & & June 2006 \\
\hline
\end{tabular}

Note: All studies included adults of both sexes and used BMI to define obesity. Abbreviations: Ref, reference; M, male; F, female; BMI, body mass index. 


\section{Discussion}

This review showed that the prevalence of overweight and obesity in Nigeria ranged from $20.3 \%-35.1 \%$, and $8.1 \%-22.2 \%$, respectively. Only four studies met the inclusion criteria. One of the studies that met the inclusion criteria was carried out in the north-eastern region of Nigeria (Maiduguri), one was from north-central Nigeria (Ilorin), and the remaining two were from two different states in south-western Nigeria, Lagos State and Osun State (Ile-Ife is a town in Osun). None of the studies carried out in the south-eastern, and southern parts of the country met the inclusion criteria.

There is a dearth of data pertaining to systematic reviews on overweight and obesity in the country. A systematic literature review to identify relevant studies on Nigerians and Ghanaians was carried out on papers on Nigeria and Ghana using MEDLINE 1966-2005, EMBASE 1980-2005, and cited references. The review gave a prevalence rate of obesity of $8.8 \%$ (confidence interval [CI] 7.0-10.6) in Nigeria in the year $2000 .^{23}$ A meta-analysis review carried out in 2007 provided a prevalence of obesity of $10.0 \%(95 \%$ CI, 6.0-15.0). ${ }^{24}$ Women were more likely to be obese than men, with odds ratios of 3.16 (95\% CI, 2.51-3.98) and 4.79 (95\% CI, 3.30-6.95) in urban and rural areas, respectively. In 2005, the WHO reported that the prevalence of obesity in Sub-Saharan African countries ranges between 3.3\% and $18.0 \%$, and that obesity has become a leading risk factor for diabetes mellitus and cardiovascular diseases in the urban areas of Africa. $^{25}$

It is evident that the prevalence rate of obesity is rising based on the fact that the two systematic reviews mentioned above were carried out on earlier articles that were published on obesity in the region.

The studies mentioned above that were selected for review also dealt with the possible predisposing factors of overweight and obesity and these include female sex, high socioeconomic class, sedentary lifestyle, age above 40 years, and a high energy diet. ${ }^{13,20-22}$ In their study, Oyeyemi et $\mathrm{al}^{20}$ also showed that environmental factors play a great role in promoting overweight and obesity. The researchers noted that the environmental attribute associated with the highest likelihood of being overweight was the absence of "beautiful things" in the neighborhood. Other factors included the presence of garbage, offensive odor in most streets, high crime rates at night, and high traffic; these factors discouraged walking and promoted overweight and obesity. Amira et al stated in their survey that the higher prevalence of overweight and obesity found in their study could be attributed to the urban nature of
Lagos and changes in behavioral patterns, such as Westernized lifestyle and diet and more sedentary jobs. ${ }^{13}$

Systematic reviews of the literature on overweight and obesity carried out in other parts of the world also showed a high prevalence of overweight and obesity. ${ }^{26-28}$ These reviews showed that the problems of overweight and obesity are not limited to Nigeria alone; however, this is a global issue that has to be addressed by individual countries.

This review indicated that the prevalence of overweight and obesity in Nigeria is on the rise. There is a need for the relevant agencies involved in health management in the country to pay more attention to combating this menace. Most of the predisposing factors are known from indigenous studies. There is a need to educate the masses about these predisposing factors through the use of media advertising; with the aid of religious leaders; in educational institutions; and so on. There is also a need to provide more recreational facilities in cities and towns in the country. The costs and benefits of addressing these health disorders is enormous both to the country and to the individuals involved.

\section{Limitation}

This systematic review highlighted the range of prevalence rates of overweight and obesity in Nigeria; however, the fact that a low percentage of the papers reviewed met the inclusion criteria points to the fact that most of the papers were poorly researched. This fact does not in any way undermine the review.

\section{Acknowledgments}

Chukwuonye conceived and drafted the manuscript. Ohagwu, Imoh, and John were involved in the literature search and data analysis. Ejiji, Chuku, and Ogah played a great role in critically revising the manuscript. Oviasu participated in the study design, and also provided input in drafting of the manuscript. All authors meticulously read and approved the final manuscript.

\section{Disclosure}

The authors report no conflicts of interest in this work.

\section{References}

1. Sani MU, Wahab KW, Yusuf BO, Gbadamosi M, Johnson OV, Gbadamosi A. Modifiable cardiovascular risk factors among apparently healthy adult Nigerian population - a cross sectional study. BMC Res Notes. 2010;3:11.

2. Oladapo OO, Salako I, Sodiq O, Shoyinka K, Adedapo K, Falase AO. A prevalence of cardiometabolic risk factors among a rural Yoruba southwestern Nigerian population: a population-based survey. Cardiovasc $J$ Afr. 2010;21(1):26-31. 
3. World Health Organization. Technical Report Series. Geneva, Switzerland: World Health Organization; 1995. Physical Status: The Use and Interpretation of Anthropometry. 854. 1-1-9950.

4. World Health Organization. Obesity and overweight [webpage on the Internet]. Geneva, Switzerland: World Health Organization; 2011 [updated Mar 2011]. Available from: http://www.who.int/mediacentre/ factsheets/fs311/en/print.html. Accessed September 17, 2012.

5. Obesity: preventing and managing the global epidemic. Report of a WHO consultation. World Health Organ Tech Rep Ser. 2000;894:i-xii, $1-253$.

6. Rivera JA, Barquera S, Campirano F, Campos I, Safdie M, Tovar V. Epidemiological and nutritional transition in Mexico: rapid increase of non-communicable chronic diseases and obesity. Public Health Nutr. 2002;5(1A):113-122.

7. Filozof C, Gonzalez C, Sereday M, Mazza C, Braguinsky J. Obesity, prevalence and trends in Latin-American countries. Obes Rev. 2001;2(2):99-106.

8. Bray GA. Complications of obesity. Ann Intern Med. 1985; 103(6 Pt 2): 1052-1062.

9. Wolf A. What is the economic case for treating obesity? Obesity Res. 1998;6 Suppl 1:2S-7S.

10. Wolf AM, Colditz GA. Current estimates of the economic cost of obesity in the United States. Obesity Res.1998;6(2):97-106.

11. Finkelstein EA, Trogdon JG, Cohen JW, Dietz W. Annual medical spending attributable to obesity: payer- and service-specific estimates. Health Aff (Millwood). 2009;28(5):w822-w831.

12. Bakari AG, Onyemelukwe GC, Sani BG, Aliyu IS, Hassan SS, Aliyu TM. Obesity, overweight and under weight in suburban northern Nigeria. Int J Diabetes \& Metabolism. 2007;15:68-69.

13. Amira CO, Sokunbi DOB, Dolapo D, Sokunbi A. Prevalence of obesity, overweight and proteinuria in an urban community in South West Nigeria. Nigerian Medical Journal. 2011;52(2):110-113.

14. Ulasi II, Ijoma CK, Onwubere BJ, Arodiwe E, Onodugo O, Okafor C. High prevalence and low awareness of hypertension in a market population in enugu, Nigeria. Int J Hypertens. 2011;2011: 869675.

15. Adegoke OA, Adedoyin RA, Balogun MO, Adebayo RA, Bisiriyu LA, Salawu AA. Prevalence of metabolic syndrome in a rural community in Nigeria. Metab Syndr Relat Disord. 2010;8(1):59-62.

16. Ejim EC, Okafor CI, Emehel A, et al. Prevalence of cardiovascular risk factors in the middle-aged and elderly population of a nigerian rural community. J Trop Med. 2011;2011:308687.

17. Amole IO, OlaOlorun AD, Odeigah LO, Adesina SA. The prevalence of abdominal obesity and hypertension amongst adults in Ogbomoso, Nigeria. African Journal of Primary Health Care \& Family Medicine. 2011;3(1): 5 pages. Available from: http://www.phcfm.org/index.php/ phcfm/article/view/188. Accessed September 17, 2012.
18. Alberti KG, Eckel RH, Grundy SM, et al; International Diabetes Federation Task Force on Epidemiology and prevention; Hational [sic] Heart, Lung, and Blood Institute; American Heart Association, et al. Harmonizing the metabolic syndrome: a joint interim statement of the International Diabetes Federation Task Force on Epidemiology and prevention; National Heart, Lung, and Blood Institute; American Heart Association; World Heart Federation; International Atherosclerosis Society; and International Association for the Study of Obesity. Circulation. 2009;120;1640-1645.

19. National Cholesterol Education Program (NCEP) Expert Panel on Detection, Evaluation, and Treatment of High Blood Cholesterol in Adults (Adult Treatment Panel III). Third Report of the National Cholesterol Education Program (NCEP) Expert Panel on Detection, Evaluation, and Treatment of High Blood Cholesterol in Adults (Adult Treatment Panel III) final report. Circulation. 2002;106:3143-3421.

20. OyeyemiAL,Adegoke BO, OyeyemiAY, Deforche B, De Bourdeaudhuij I, Sallis JF. Environmental factors associated with overweight among adults in Nigeria. Int J Behav Nutr Phys Act. 2012;9:32.

21. Adedoyin RA, Mbada CE, Balogun MO, Adebayo RA, Martins T, Ismail S. Obesity prevalence in adult residents of Ile-Ife, Nigeria. Nig Q J Hosp Med. 2009;19(2):100-105.

22. Desalu OO, Salami AK, Oluboyo PO, Olarinoye JK. Prevalence and socio-demographic determinants of obesity among adults in an urban Nigerian population. Sahel Medical Journal. 2008;11(2):61-64.

23. Abubakari AR, Bhopal RS. Systematic review on the prevalence of diabetes, overweight/obesity and physical inactivity in Ghanaians and Nigerians. Public Health. 2008;122(2):173-182.

24. Abubakari AR, Lauder W, Agyemang C, Jones M, Kirk A, Bhopal RS. Prevalence and time trends in obesity among adult West African populations: a meta-analysis. Obes Rev. 2008;9(4):297-311.

25. World Health Organization Regional Committee for Africa. Cardiovascular diseases in the african region:current situation and perspectives. Fifty-fith session. Maputo, Mozambique, 22-26 August 2005. Provisional Agenda Item 8.6. http://www.who-africa.org/index.php?option=com_ docman\&task=do c_download\&gid $=2305 \&$ Itemid $=2111$.

26. Musaiger AO. Overweight and obesity in eastern mediterranean region: prevalence and possible causes. J Obes. 2011;2011: 407237.

27. Wang Y, Beydoun MA. The obesity epidemic in the United States gender, age, socioeconomic, racial/ethnic, and geographic characteristics: a systematic review and meta-regression analysis. Epidemiol Rev. 2007;29:6-28.

28. Berghöfer A, Pischon T, Reinhold T, Apovian CM, Sharma AM, Willich SN. Obesity prevalence from a European perspective: a systematic review. BMC Public Health. 2008;8:200.

Diabetes, Metabolic Syndrome and Obesity: Targets and Therapy

Dovepress

\section{Publish your work in this journal}

Diabetes, Metabolic Syndrome and Obesity: Targets and Therapy is an international, peer-reviewed open-access journal committed to the rapid publication of the latest laboratory and clinical findings in the fields of diabetes, metabolic syndrome and obesity research Original research, review, case reports, hypothesis formation, expert opinion and commentaries are all considered for publication. The manuscript management system is completely online and includes a very quick and fair peer-review system, which is all easy to use. Visit http://www.dovepress.com/testimonials.php to read real quotes from published authors. 